\title{
White Spot Lesion
}

National Cancer Institute

\section{Source}

National Cancer Institute. White Spot Lesion. NCI Thesaurus. Code C60714.

A chalky white area that appears on a tooth surface indicating the presence of decalcified enamel and the potential to advance to cavitation. 